\title{
ECG diagnostic de TRIN, tachycardie par réentrée intranodale
}

\section{Diagnostic ECG of AVNRT, atrioventricular nodal reentrant tachycardia}

\section{P. Taboulet}

Reçu le 18 avril 2013; accepté le 22 mai 2013

(C) SFMU et Springer-Verlag France 2013

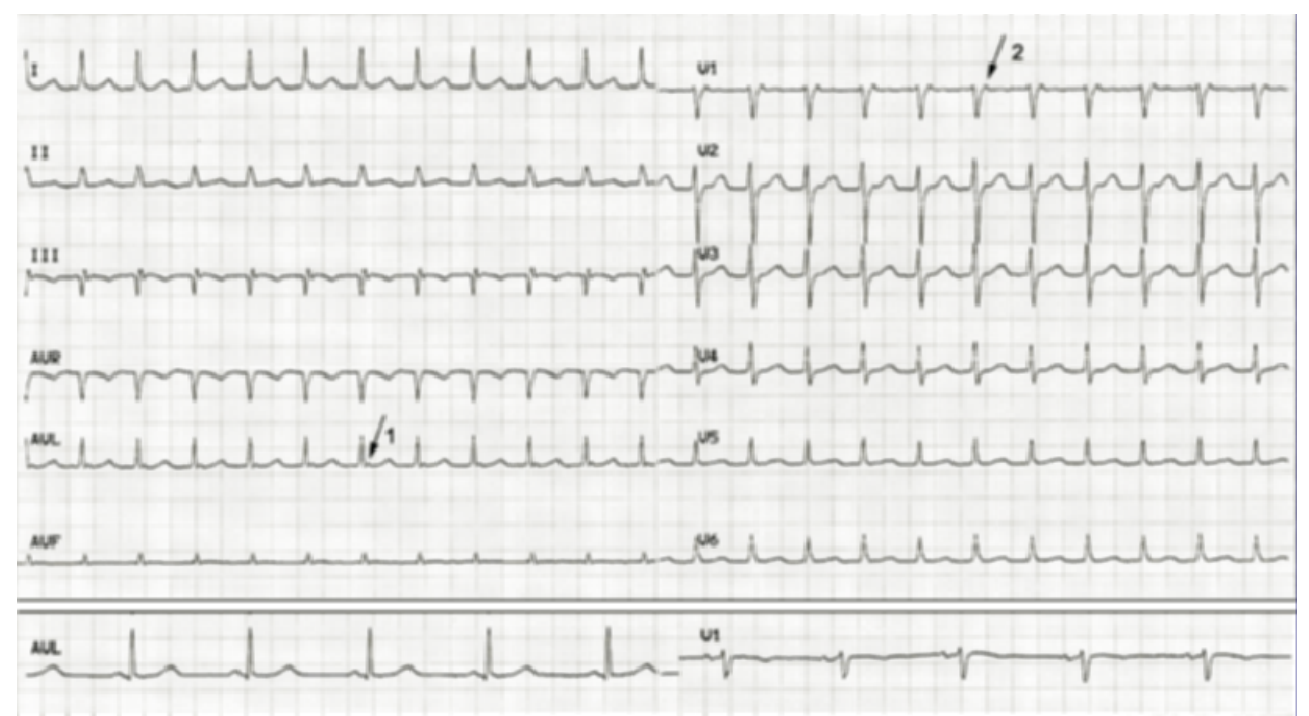

Fig. 1 Haut : tachycardie par réentrée intranodale (TRIN). Notez l'onde $P$ rétrograde qui suit immédiatement les complexes QRS en VL (flèche 1) et V1 (flèche 2). Bas : rythme sinusal. Notez la disparition de l'onde $P$ rétrograde

Une femme de 61 ans consulte aux urgences pour palpitations incessantes. Elle a pris auparavant un comprimé de propranolol $40 \mathrm{mg}$, car elle fait parfois des crises de tachycardie non étiquetée. Les ECG inscrivent une tachycardie, d'abord à $165 /$ min puis à 135/min, à complexes QRS fins et normaux, rebelle aux manœuvres vagales. Les dérivations VL et V1 révèlent une déflexion atypique qui suit immédiatement les complexes QRS et suggère une onde $P$ rétrograde précoce.

L'administration intraveineuse de diltiazem restaure le rythme sinusal et la déflexion atypique disparaît (Fig. 1), ce qui conforte a posteriori l'hypothèse d'une onde $P$ rétro- grade. Cette onde $P$ rétrograde per tachycardie, lorsqu'elle est très précoce $(<70 \mathrm{~ms}$ du début du QRS), est la signature d'une activation quasi simultanée des oreillettes et des ventricules, en raison d'une microréentrée en boucle au sein du nœud auriculoventriculaire. On parle alors de « tachycardie réciproque par réentrée intranodale » ou TRIN. Ce mécanisme de microréentrée explique environ $40 \%$ des tachycardies jonctionnelles, une macroréentrée par faisceau accessoire expliquant quasiment toutes les autres.

Cet exemple illustre l'importance des dérivations VL et V1 pour classer une tachycardie supraventriculaire.

P. Taboulet $(\bowtie)$

Hôpital Saint-Louis,

Assistance publique-hôpitaux de Paris,

service des urgences, 1, avenue Claude Vellefaux,

F-75010, Paris, France

e-mail : pierre.taboulet@sls.aphp.fr 